\title{
Research on the Integrative Development of the "Three New Aspects" Related to Cultural Industry and the Mainstream Ideology
}

\author{
${ }^{1}$ Dalian Art College, Dalian, Liaoning, China \\ *Corresponding author. Email: 728572159@qq.com
}

$\mathrm{Na}$ Wang ${ }^{1, *}$

\begin{abstract}
Cultural industry is an emerging carrier of the trend of economic and cultural integration. As economic development has entered a new normal, the number of new industries, new forms of business and new models related to the cultural industry (the "three new aspects") has been on the rise, becoming an important engine driving China's steady economic growth and the transformation and upgrading of economic structure and effectively offsetting the impact of the weakening of traditional growth drivers on the economy. At the same time, cultural industry has a unique impact on the country's cultural soft power in terms of resource form, social evaluation, ideology and national education. It enhances the guiding and penetrating power of the mainstream ideology in the cultural industry, and is the inevitable appeal of the ideology construction in the new era. On the basis of analyzing the "three new aspects" related to cultural industry, this paper discusses the path and way of integrating the mainstream ideology with new industries, new forms of business and new models.
\end{abstract}

Keywords: cultural industry, "three new aspects", mainstream ideology, integration

\section{INTRODUCTION}

Being both economically and ideologically significant is the most prominent characteristic that sets cultural industry apart from traditional agriculture, industry and service industry. Through cultural products, cultural industries can conduct emotional communication, value proposition communication and national position expression. In the content, it reflects the living conditions, ideological care and cultural lifestyle design of certain people, society and organizations. Therefore, cultural industry is not only an important economic industry, but also a core channel in the propaganda of a country's mainstream ideology. At the same time, with people's high understanding of the adjustment and upgrading of industrial institutions, the research on new industries, new forms of business and new business models has been upgraded from the concept to the detailed management stage of industrial classification.

*This paper is supported by the 2019 National Art and Science Planning Project "Research on Ideological Issues in New Forms of Business, New Media and New Situations" (Project No.: 19DY11). It is also a research result of the excellent project of ideological and political work in colleges and universities of the Ministry of Education in 2020, "Mechanism Exploration of the Artistic Practice of Educating People by Guiding Their Thoughts Under the Concept of 'Holistic Ideology and Political Education'".
II. THE RAPID DEVELOPMENT OF THE

"THREE NEW ASPECTS" IN CULTURAL INDUSTRIES IS THE PREMISE OF THE DIVERSIFIED DEVELOPMENT OF THE MAINSTREAM IDEOLOGY

\section{A. The cultural industry continues to develop strongly, providing basic resources to enhance the country's cultural soft power}

Under the guidance of the 13th Five-Year Plan, China's cultural industry has developed in an orderly way. In 2018, the added value of China's cultural industry reached 3873.7 billion yuan, an increase of 10.3 times over 2004; from 2005 to 2018, the added value of the cultural industry grew at an average annual rate of $18.9 \%, 6.9$ percentage points higher than the current GDP growth rate in the same period. The added value of cultural industries accounted for $4.30 \%$ of GDP in 2018, up from $2.15 \%$ in 2004 and $3.36 \%$ in 2012 , and its share in the national economy increased year by year. In the first half of 2019, the operating revenue of cultural and related enterprises above designated size reached 4,055.2 billion yuan, an increase of $7.9 \%$ over the same period last year. It can be seen that the total cultural economy in China has increased significantly and will take up a higher 
proportion in the national economic development at a higher growth rate.

Among cultural and related industries, news and information services $(25.1 \%)$, creative design services (12.4\%), cultural investment and operation (10.2\%), and content creation and production $(9.8 \%)$ all cover most new forms of cultural business. Among them, the revenue growth rate of the integrated broadcast control of radio and television, other Internet information services, Internet advertising services, industrial design services, Internet cultural and entertainment platforms, electronic publications publishing, wearable smart culture devices and virtual reality devices and other business types is all above $20 \%$. The development of new forms of cultural business has gained a strong momentum, expanded and innovated the field of cultural development, and led and promoted the development of China's cultural industry, which will continue to grow at a high speed for some time to come ("Fig. 1").

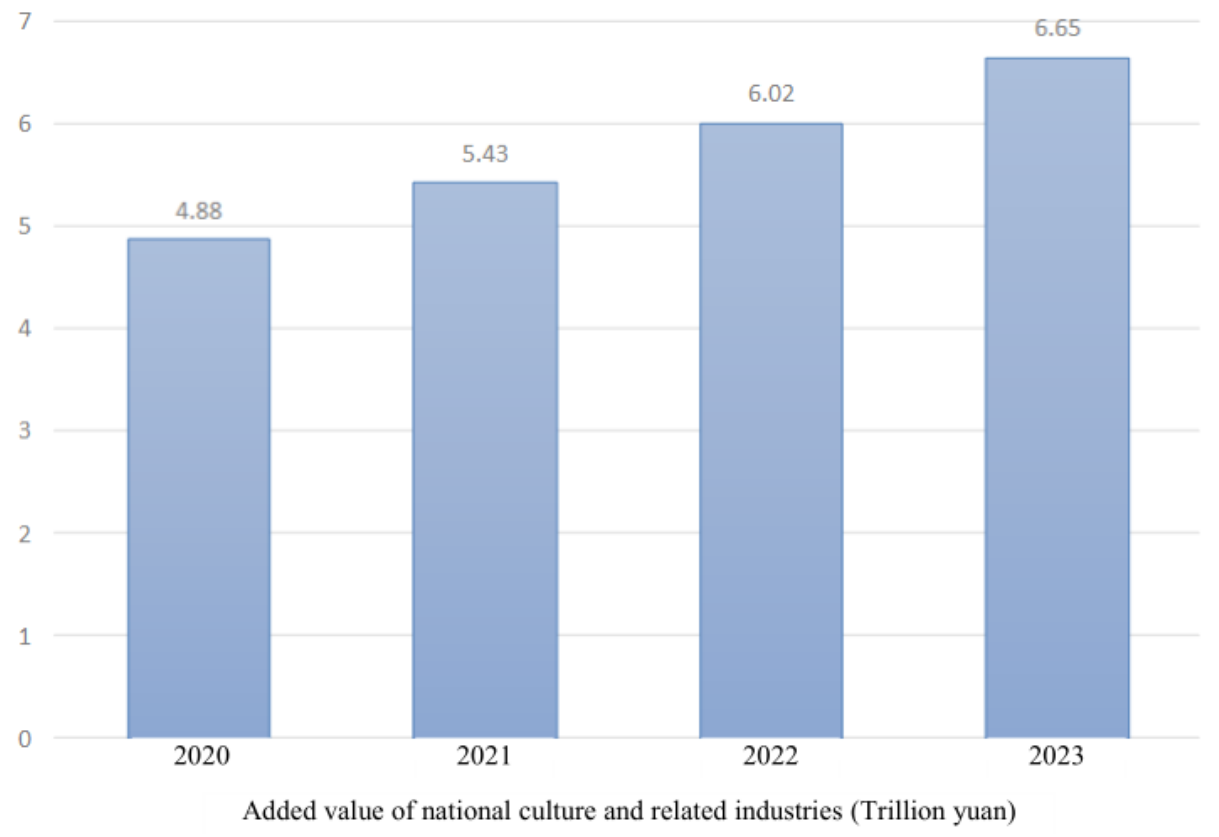

Fig. 1. Statistics and forecast of national cultural and related industries' added value.

a. Data Source: 2019 Chinese Cultural Industry Market status and Development Trend Analysis "Internet +" brings four industrial development opportunities, Flush Finance, 2019.6.8.

B. The clear classification of the "three new aspects" in cultural industry provides guidance for the integration of diversified ideology and culture

In August 2018, according to the "National Industries Classification" (GB/T 4754-2017), the National Bureau of Statistics formulated and released "The Statistical Classification of New Industries, New Forms and New Business Models (2018)" (hereinafter referred to as the "Classification of the Three New Aspects") after carefully summarizing and sorting out local and departmental opinions on the statistical classification of the "three new aspects". The basic starting point is a focus on reflecting the activities related to the "three new aspects" such as advanced manufacturing, Internet Plus, innovation and entrepreneurship, and cross-border integrated management, etc. The Cultural Industry Review (whcypl) studied and sorted out the statistical contents of the "Classification of the Three New Aspects", and found that the statistical classification of new forms of business and new business models related to the cultural industry accounted for a large proportion and became an important part of the "Three New aspects" economy. In the nine categories of the "Classification of the Three New Aspects", the new forms of business and new business models of cultural (including cultural and tourism integration) cover six categories: advanced manufacturing, Internet and modern information technology services, modern technology services and innovation and entrepreneurship services, modern productive service activities, new lifestyle service activities, and modern comprehensive management activities. Among them there are 12 middle classes and 62 small classes for layered column items.

The 12 middle classes includes items of a new generation of information technology equipment manufacturing, modern information transmission service, Internet platform (+) Internet, Internet information and other services, software development, production, design and production of digital content 
services and other modern technology services, modern business services, catering services, cultural entertainment services, modern tourism service, modern city commercial integrated management services. Among them, new forms of cultural business based on modern information technology and Internet platform become the biggest highlight of classified statistics.

Based on the characteristics of the "Classification of the Three New Aspects", the author believes that "new forms of cultural industry" are new forms of cultural industry driven by the contemporary fashion and life trend with the support of new and high technologies such as digitalization and Internet. It mainly includes three levels. First, high and new digital technologies have promoted the transformation of traditional and normal cultural and creative industries into high-end ones, giving rise to a large number of new forms of business, such as creative design, animation, online games, Internet economy, modern convention and exhibition industry, modern advertising industry, electronic (digital) commerce, and network television. Second, the emergence of new media and new industries has turned Internet platforms into infrastructure for the development of cultural enterprises, enabling them to achieve the goal of removable operation ("Fig. 2"). Third, with the diversification of cultural formats, new business models are increasingly refining the cultural market, and satisfying the needs of personalized consumer groups has become a new direction of competition. For example, with the continuous evolution of cloud computing, VR, AR and other new technologies, the Internet giant enterprises are rushing to make their layout, and the linkage of film, game, culture, education and industry integration will become the trend. Mobile electronic sports, Internet film and television become new points to be explored. On October 21, 2019 in the Sub-forum of Media Convergence of the 6th World Internet Conference, chairman of the Asian Electronic Sports Federation, vice president of The Sports Federation and Olympic Committee of Hong Kong (China) Huo Qigang mentioned, "Judging by the national team's line-up for last year's Asian Games in Jakarta and the results it has achieved, e-sports is becoming increasingly mainstream." "In 2019, online statistics of e-sports participants worldwide reached 4.1 billion, and industry practitioners reached 1.76 billion," Huo said. He further explained that these practitioners are not only e-sports players, but also professional online broadcasting of e-sports, offline stage design and production of various professional e-sports products.

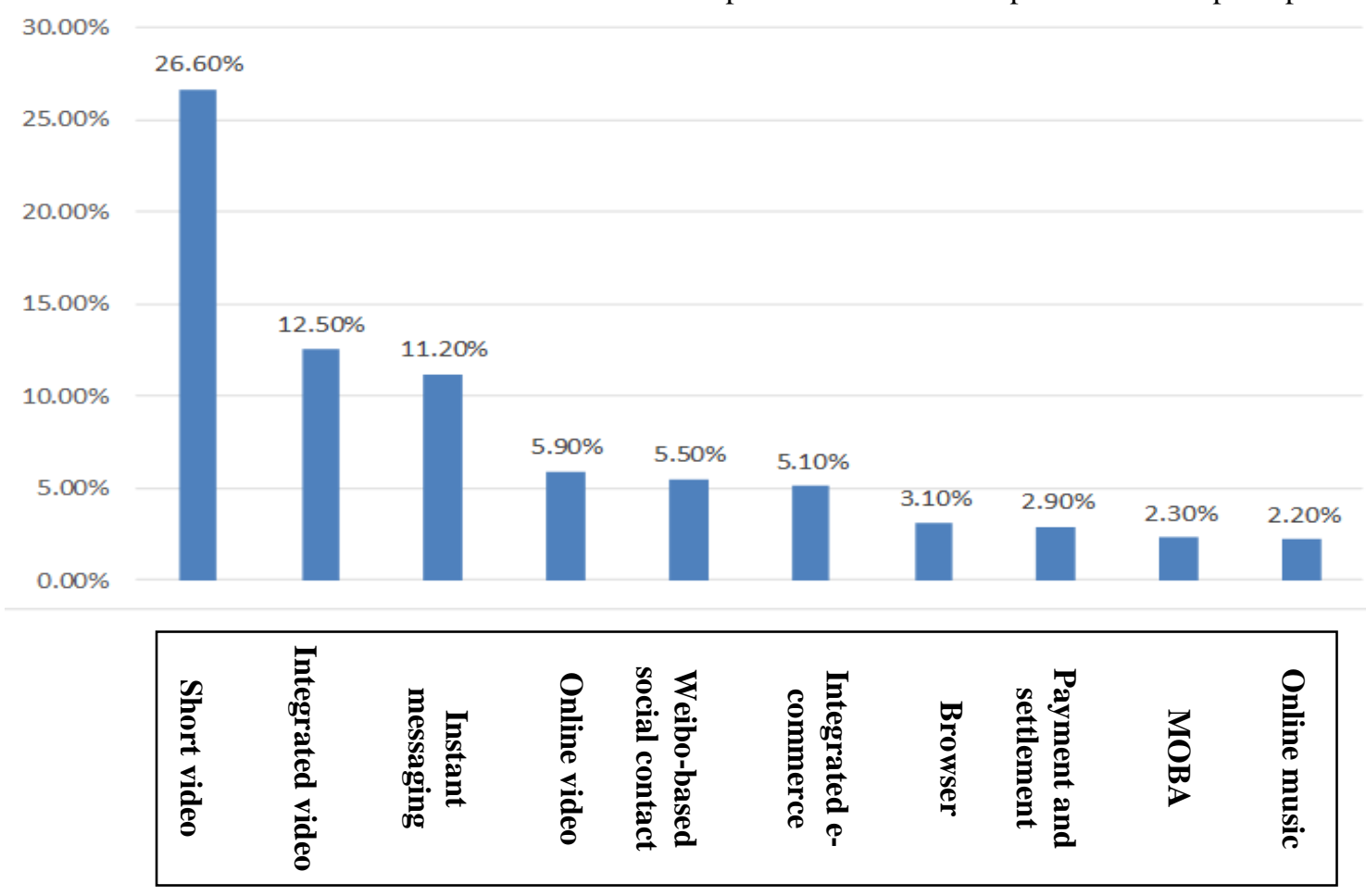

Fig. 2. Top 10 year-on-year increase of users' total usage in March. 


\section{PROBLEMS AND COUNTERMEASURES OF THE INTEGRATION OF "THREE NEW ASPECTS" AND MAINSTREAM IDEOLOGY IN CULTURAL INDUSTRY}

\section{A. Following the law of market economy and exporting mainstream ideology by making full use of the characteristics of "new three aspects" in the cultural industry}

1) Strengthening the adaptability of mainstream ideology to the rapid development of the "three new aspects" in cultural industries, and realizing the dual aims of economic value and ideological communication of culture: With the rapid development of the "three new aspects" in cultural industries, all aspects of China's cultural industry are undergoing tremendous changes, and the mainstream ideology, together with other social components, is also undergoing profound transformation. However, the gap between the selfdevelopment of mainstream ideology and the pace of adjustment of industrial economy is getting bigger and bigger due to the lag of concept transformation and the lack of innovation in system and mechanism reform. In terms of the influence of the mainstream ideology on the creative cultural industry, its adjustment and adaptability are obviously insufficient, and the understanding of the "new three aspects" is not enough, let alone its full use. The development of cultural industry and contend for markets are becoming the core content of soft power competition in today's world. A grim situation is that international information technology groups and cultural media groups have already started to integrate the cultural resources of various countries in order to prepare for the development of new world markets. China's huge cultural market value has long been a target for Western cultural groups. Successful cases such as "Mulan", "Kung Fu Panda" and "Kung Fu Panda 2" use a large number of Chinese cultural elements and life concepts to create a refreshing cultural feast, achieving high ratings and huge box office and profits in China and the world. In addition, many classic Chinese works such as "Journey to the West", "Chronicles of The Three Kingdoms" and "Water Brothers" have been developed and transformed by the cultural capital of the United States, Japan and other countries into films and games that are popular all over the world, and have become strong competitors of China's cultural industry. From the above examples, it can be clearly seen that the output of foreign ideology has been transformed from the original "hard coverage" to the secondary mining of Traditional Chinese cultural resources. After integrating their domestic ideology into it, "soft integration" has been achieved through the sales of cultural products.

2) Discarding the evaluation criteria and methods that the mainstream ideology adheres to the form and content of cultural communication, and quickly integrating the development laws of "three new aspects": Against the background of "Internet +", the cultural industry and the Internet gradually become deeply integrated, which greatly enriches the connotation and extension of the cultural industry and gradually forms a brand new cultural industry chain different from the traditional cultural industry chain. With the emergence of the "Three new aspects" in the cultural industries, all fields of Chinese society are undergoing profound changes, and the mainstream ideology and other social components are also undergoing profound transformation. However, due to the lag of concept transformation and the lack of innovation in system and mechanism reform, the mainstream ideology appears to be out of touch with reality in shaping, spreading, channel, influence and education, etc. Taking the value evaluation of cultural products by mainstream ideology as an example, for some non-mainstream cultural products in the traditional sense, relevant departments still focus on the frequency of vulgar content and the reflection of the "theme of the time" in works in their evaluation criteria. In terms of influencing methods, traditional administrative methods such as gag, ban, block or "once and for all" cuts are still considered as the "most reasonable" methods today. As a result, too much emphasis is placed on the authority of politics while neglecting the attribute of cultural industry, leading to the decline of the value guidance of mainstream ideology.

In order to achieve fast and effective propagation of mainstream ideology, it is necessary to make perfect integrations in combination with the characteristics of the "three new aspects". Taking the use of new media for mainstream value dissemination, it is important to fully understand its six characteristics: strong interactivity, mass information carrying function and information fragmentation, resource sharing, hypertext and hyperlink application and multimedia support, strong personality and initiative and virtualization and socialization. These have formed the absolute difference with the traditional unidirectional, popular, passive communication mode.

Based on the above analysis, the author believes that there are three respects to explore in the integration of mainstream ideology and new media:

In terms of the convergence of media forms, with the continuous development of new media, its 
marketing platforms are diversified. Mainstream ideology should be fully integrated with community platforms, short video platforms, live streaming platforms and social platforms.

In terms of the subject of communication, the opinion leaders in each platform and vertical field should be used as much as possible. They have influence and discourse power in the new media user group, and these opinion leaders should be cultivated and guided to become important communicators of mainstream ideology. In the Spring Festival Gala of Liaoning TV in 2020, we saw two net doyen Li Jiaqi and Lier. They are opinion leaders in the marketing environment of new media, who can expand the popularity and exposure of products and directly drive consumption, with their own huge virtual community. This time they appeared on the screen as poverty alleviation officials, which is a very good way to integrate.

In the way of communication, it is easy for the monotonous content of multiple times, repeated publicity, to make the audience feel tired and inimical Compared with direct and rigid education, event communication and content communication with more creation are more likely to be favored by the audience in the form of soft implantation. Data from iiMedia Research-"2019 China New Media Marketing Value Special Report" shows that images and texts for cultural and entertainment products accounted for $91.5 \%$ in 2018 , and by 2019 , the proportion had risen to $95 \%$. That is to say, now people have come to the era of "receiving information through images", so the dissemination of mainstream ideology should cater to people's habit of receiving information and carry out diversified creative communication.

\section{B. Strengthening ideological self-discipline and promoting the orderly development of the "three new aspects" in cultural industries with the construction of mainstream ideology}

1) The "three new aspects" in cultural industry cannot develop healthily without a good mainstream ideology ecological construction environment: Under the condition of market economy, the pursuit of economic benefits is the nature of cultural enterprises. However, if cultural enterprises just pursue economic benefits blindly with a neglect of social benefits and lack of supervision, it will easily lead to the marginalization of mainstream ideology in the cultural industry. On the Internet, people can see some empty and nonsensical, fast-food, non-mainstream, bourgeois culture products, as well as some cultural products with the so-called "universal" value. There are also some cultural enterprises are making playful interpretation of history, spoofing, defaming and even attacking authoritative national heroes and moral models under the guise of creativity, in order to attract eyes, in exchange for attention and attraction of products. At the same time, some foreign cultural products also attack the "three reflections" of the Chinese people by promoting the western bourgeois ideology, which dilutes the dominance and authority of the mainstream ideology in the cultural field.

2) Realizing the interconnected development of "three new aspects" of cultural industry with the construction of ideological self-discipline: Ideological self-discipline is mainly reflected in the conscious awareness of mainstream ideology on its influence and intervention space, and a high level of vigilance and disposition attitude towards "extreme ideology and vulgarization of ideology". It is necessary to construct the benign structure between the cultural industry and the mainstream ideology in a scientific approach, and the cultural industry should unite people and gather strenth with the help of the mainstream ideology.

Taking the digital content industry as an example, in 2018, the actual sales revenue of China's game market reached 214.4 billion yuan. In 2019, the actual sales revenue of Chinese game market reached 230.88 billion yuan, with a year-on-year growth of $7.7 \%$. After years of rapid growth, the digital content industry has entered a new stage of development. As the growth rate of the number of users slows down and market competition intensifies, the development model of "urban sprawl" and blind expansion of scale is no longer sustainable. Therefore, it is imperative to adjust and upgrade the industry and build an ideological and self-regulatory environment. At the opening ceremony of the 17th China International Digital Entertainment Industry Conference in 2019, Guo Yiqiang, director of the Publicity Department of the CPC Central Committee, pointed out that, from this year on, the National Press and Publication Administration will strengthen the administration of examination and approval, hold higher standards on content of games related to chess and cards, fishing and other games related to harem fight and official circles, which are strongly rejected by the public, so as to resolutely correct undesirable tendencies in creation and production. At the same time, measures should be taken to encourage and support enterprises to publish and operate games with correct value orientation, rich cultural connotation, and edutainment, so as to form an approval mechanism with clear guidance, clear standards, and strict standards.

\section{CONCLUSION}

At the symposium commemorating the 70th anniversary of the founding of The China Federation of Literature and Art and the China Writers' Association, General Secretary Xi Jinping sent a congratulatory 
letter to the work of literature and art consciously assume the mission, create and produce excellent products, and constantly create a new situation. To rapidly develop the "three new aspects" in the cultural industry, it is necessary to follow the guidance of $\mathrm{Xi}$ Jinping Thought on Socialism with Chinese Characteristics for a New Era and thoroughly study and implement the important directives of General Secretary Xi Jinping on ideological and propaganda work; it is necessary to strengthen consciousness of the need to maintain political integrity, think in big-picture terms, uphold the leadership core, and keep in alignment; it is necessary to fortify our confidence in the socialist path, theories, system and culture with Chinese characteristics; it is necessary to resolutely uphold the core position of General Secretary Xi Jinping in the CPC Central Committee, and the authority and centralized, unified leadership of the CPC Central Committee. And great efforts should be made to create outstanding works that are worthy of the times, the people and the nation, and contribute to the prosperity and development of socialist cultural undertakings and the building of a country with strong socialist cultural. At the same time, the development of the "three new aspects" in cultural industries still strictly follows the principle of survival of the fittest in the market economy. Therefore, under the logic of "content is king", cultural enterprises should focus on the quality of products through their own production mode. They need to make corresponding adjustments from the aspects of creativity in product production, project approval, resources, talents, technical means and packaging publicity, etc., in order to produce new and better cultural products with new ideas, new production methods and new forms of expression.

\section{References}

[1] Yuan Shenzhi. Study on the Possibility and Realization of the Integration of mainstream Ideology and Creative Cultural Industry [J]. Journal of Guangdong Industry Technical College, 2018 (17): 68-71. (in Chinese)

[2] Zhao Xuelin, Lu Jing. Functional Analysis of Cultural Industry Enhancing National Cultural Soft Power [J]. Studies on the Socialism with Chinese Characteristics, 2011. 6. (in Chinese)

[3] Hu Jingjing. Substance and Dilemma: Contemporary Interpretation of Mainstream Ideological Responsibility in Cultural Industry [J]. Academic Forum, 2014 (277), 124-128. (in Chinese)

[4] Wang Jun. What Are the New Industries, New Forms of Business and New Models of Cultural Industry Released by the State. [EB/OL]. http://www.cjiyou.net/html/201808/481318.htm,2018-08-30. (in Chinese)

[5] China Game Association (GPC) \& International Data Corporation (IDC). 2019 China Game Industry Report: In 2019, China's Game Market Revenue Reached 230.88 Billion Yuan, with 640 Million Users [EB/OL]. https://www.gameres.com/859559.html,2019-12-19. Chinese)
[6] Economic Daily, A Report Released by the National Bureau of Statistics Shows That the Value Added of the Cultural Industry Has Increased Year by Year in the National Economy [EB/OL] http://www.gov.cn/xinwen/2019-

07/26/content_5415564.htm,2019-07-26. (in Chinese) 